\title{
Pathologic Fracture and Vitamin D Deficiency in Pediatric Patient with Osteogenesis Imperfecta Type IV
}

\author{
Arya Wisnu Prayoga*, I Made Arimbawa, I Wayan Bikin Suryawan, I Made Dharma Yuda \\ Department of Child Health, Udayana University, Denpasar, Indonesia \\ Email address: \\ aryacarter1989@gmail.com (A. W. Prayoga) \\ ${ }^{*}$ Corresponding author \\ To cite this article: \\ Arya Wisnu Prayoga, I Made Arimbawa, I Wayan Bikin Suryawan, I Made Dharma Yuda. Pathologic Fracture and Vitamin D Deficiency in \\ Pediatric Patient with Osteogenesis Imperfecta Type IV. International Journal of Diabetes and Endocrinology. Vol. 6, No. 1, 2021 , pp. $31-35$. \\ doi: $10.11648 /$ j.ijde.20210601.16
}

Received: January 5, 2021; Accepted: January 19, 2021; Published: January 28, 2021

\begin{abstract}
Osteogenesis imperfecta (OI) is a hereditary disorder characterized by increased tendency for bone fractures due to high fragility. The clinical and radiological features of OI manifest in different age groups, although the disease is congenital in nature. Clinical manifestation of OI included laxity of the ligaments, blue sclera, growth retardation, and scoliosis. The most important oral finding in OI is the presence of yellowish-brown-colored brittle teeth characteristic of dentinogenesis imperfecta. A 13 years-old male brought to hospital with chief complaints of fracture upper and lower limbs. The fractures due to minor trauma when he felled from standing position. He also complained about dentition. Teething is said to be disturbed, imperfect and brown colour. Radiology examination showed complete fracture et regio left femur. Bone Marrow Density examination showed low bone mass. Laboratory examination showed hypocalcemia, vitamin D insufficiency and normal parathyroid hormone. On the $5^{\text {th }}$ days of hospitalization patient got surgery from orthopedic specialist for primary treatment of the fracture. The others treatment were given included zolendronat acid, calcitriol and calcium carbonate medication until patient discharged from hospital. Osteogenesis imperfecta could be treated and had well prognostic with the early diagnosed and proper treatment. Management of osteogenesis imperfecta involve multidisciplinary such as pediatric endocrinologists, orthopedics, medical rehabilitation, child development and nutrition.
\end{abstract}

Keywords: Osteogenesis Imperfecta, Pathologic Fracture, Vitamin D Deficiency

\section{Introduction}

Osteogenesis imperfecta (OI) is a heritable disorder of bone formation that may affect more than 1:10.000 individuals. It is characterized by bone fragility due to low bone mass giving an increased fracture incidence [1]. The bone fragility has led to the adoption of the lay name of "brittle bone disease". The heritable nature of the disorder distinguishes it from idiopathic juvenile osteoporosis, although clinical osteoporosis is also a consequence of OI. Although in OI patient serum calcium and vitamin D metabolite levels were normal.

The diagnosis of OI may be based on clinical, physical examination, and laboratorium. Common clinical findings include triangular facies, blue- or gray-tinted sclerae, chest deformities such as pectus excavatum or carinatum, dentinogenesis imperfecta, skin hyperlaxity, and joint hypermobility. These are all features that one might expect to be associated with a disorder involving type I collagen, though such a relationship is not absolute. When OI patient having blue sclera and dentinogenesis imperfecta commonly have mutations in type I collagen genes [2].

Radiology examination of OI include osteopenia, vertebral compressions (codfish vertebrae), and wormian bones. Osteogenesis imperfecta may present with wormian bones in the sutures of the skull and may be of decreased height and have skeletal deformity. Molecular analysis from cultured fibroblasts test for the genes encoding collagen I (COL1A1 and COL1A2) from a skin biopsy can used for diagnosis OI [2, 3].

Osteogenesis imperfecta has been recognized as a disease entity since the $17^{\text {th }}$ century, when it was termed congenital osteomalacia. The term osteogenesis imperfecta was adopted in the late $19^{\text {th }}$ century. The original classification 
by Sillence in 1979 divided osteogenesis imperfecta into types on the basis of clinical, radiographic and genetic criteria. As more patients with OI were investigated, the broad clinical spectrum of the disease was more fully recognized and more comprehensive classification systems were adopted. The newest classification divides OI into 8 types. Type I-IV is a classification that divides OI based on clinical, radiological, and genetic aspects. Types V-VIII are types of OI that are not associated with the collagen I gene mutation and do not show a characteristic clinical picture. Type I and IV are the most common types [2,4]. The objective of this case is to describe the clinical manifestation, clinical examination and management of OI type IV.

\section{Case Illustration}

A 13 years-old male brought to the general hospital with complaints of fracture upper and lower limbs. The fractures due to minor trauma when he felled from standing position. The mechanisme of injury was not clear, patient said he was felled when he touch the electricity. Parents said that patient usually felled without any injury mechanism, but there was no history of fracture before.

Parents also complained about dentition. Teething is said to be disturbed and imperfect. After the baby teeth fell out, only a few teeth grew. Teeth that grow are said to be brown, unlike teeth in general (Figure 1). The patient's appetite is said to be good. Patients were able to consume food 3 times a day as before being sick and snacked on. Clear yellowish colored urine with a frequency of 4-6 times a day, the volume is quite a lot. The last urinate was said to be 2 hours before admitted. Complaints of fever, cough, runny nose or shortness of breath are denied.

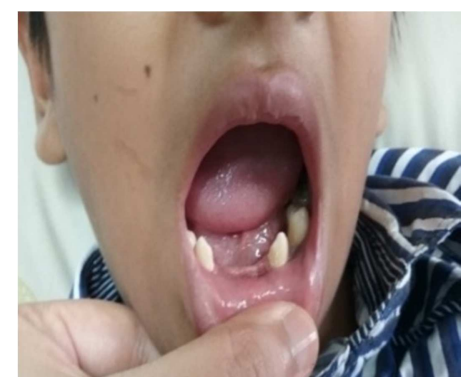

Figure 1. Clinical manifestation of dentinogenesis imperfecta in patient.

Laboratory findings with slightly decrease of calcium point $(8.9 \mathrm{mg} / \mathrm{dl})$, for the $\mathrm{CBC}$ and other electrolyte laboratory was normal result. On radiographic examination showed complete fracture with displacement, angulation, shortening and callus formation on left femur (Figure 2). The result of bone mass density (BMD) examination was low bone mass with the result point $\mathrm{Z}$-score -2.9 . On the $4^{\text {th }}$ days of hospitalization, the result of vitamin D25-OH and parathyroid hormone was seen, with the result of vitamin D25-OH was 17.6 showed insufficiency, but the parathyroid hormone shows normal result $(21.59 \mathrm{pg} / \mathrm{ml})$.

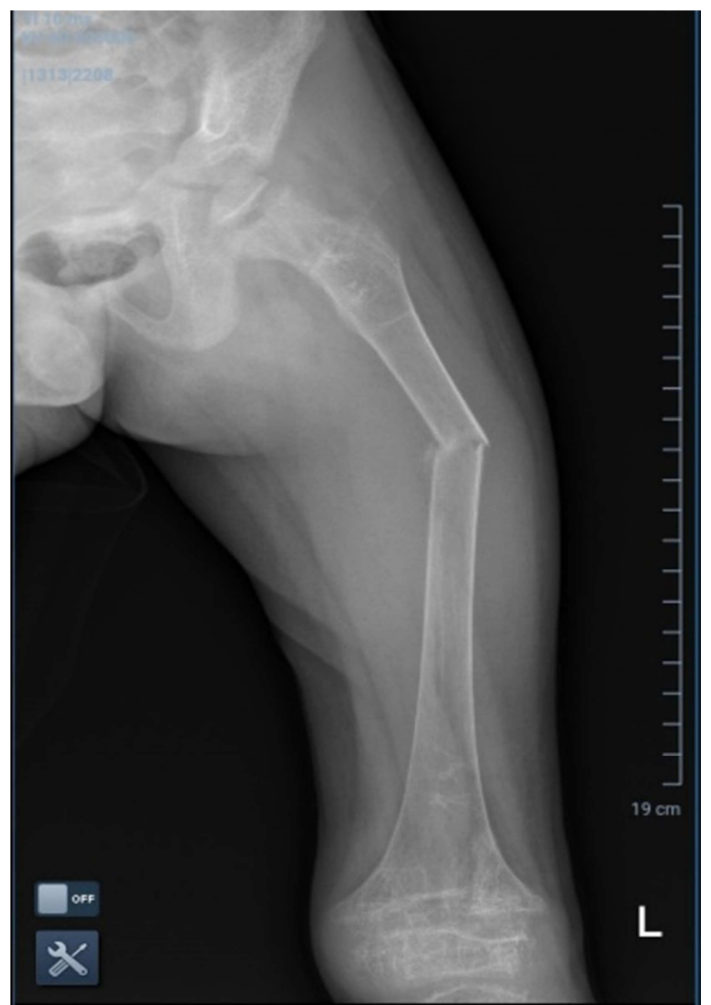

Figure 2. Femur x-ray examination showed complete fracture on the left femur.

Patient got calcium carbonate and calcitriol for the medication and planned for zoledronic acid for the further medication. On the $5^{\text {th }}$ days of hospitalization patient got open reduction and internal fixation (ORIF) on his left femur. After patient stable, on the $7^{\text {th }}$ days of hospitalization zolendronat acid was given. Patient discharged from hospital on $8^{\text {th }}$ days of hospitalization, calcium carbonate and high dose of vitamin D was continued after discharged and planned to evaluate electrolyte and vitamin $\mathrm{D}$ gradually.

\section{Discussion}

Osteogenesis imperfecta is a disorder characterized by bone fragility due to impaired collagen synthesis and modification. Collagen is a protein complex compound that has tensile strength and structure in the form of fibers that function as a bone framework. In most OI, the sufferer has little collagen type $1[1,2]$. Type 1 collagen is found in the bones, organ capsule, fascia, cornea, sclera, tendons, meninges, and dermis. Structurally, collagen type 1 consists of a left-handed helix formed by the pro-alpha 1 and pro-alpha 2 chains. Mutations at the locus coding for these chains (COL1A1 in the 17q21 chain and COL1A2 in the 7q22.1 chain) cause OI. Mutations in these genes were only detected in $85 \%$ of patients with clinical OI [3]. Starting in 2006, at least 17 genes in addition to COL1A1 and COL1A2 defects were associated with the OI phenotype [4].

Osteogenesis imperfecta is an osteoporosis disorder in children with an incidence of 1: 20.000 births. The true incidence is thought to be higher considering that there are 
pediatric patients who are undiagnosed because they have mild signs [3]. The disorder can occur in all races and ethnicities. Osteogenesis imperfecta is mostly inherited by autosomal dominant (AD) as much as $90 \%$, but spontaneous mutations can occur, especially in OI children who have healthy parents. Genetic counseling is needed to determine whether both parents have undiagnosed OI, the parent is the carrier of the mosaic gene for the dominant form of OI, or both parents or siblings are carriers of the recessive gene for OI. The main questions that should be asked of the family are regarding the height of the family members, sclera color, history of fractures, and the presence of deafness in the family members. Another child can be born with OI even though there are no abnormalities in the family members. Gene damage can occur as a spontaneous mutation so that people with OI have a $50 \%$ chance of passing on the disorder to their children [5]. In this case, there is no family history of consanguineous marriage, blue or gray sclera, skeletal abnormalities or deafness, and possible gene damage that occurs comes from a spontaneous mutation.

The diagnosis of OI is confirmed clinically, supported by radiological examination or chemical analysis. The clinical picture of OI varies from person to person, even though they suffer from the same type and / or are in the same family. Due to the mass of brittle bones, OI is often characterized by repeated fractures caused without or with minor trauma. In general, the earlier the fracture occurs, the more severe the degree of OI is suffered. The lower limb is the area most commonly affected. Femoral fracture is the most common type of fracture in the long bone, with other locations generally in the convex, transverse, or minimal displacement of the bone [3]. In this case, the patient has experienced repeated minor trauma, the history of fracture was denied by his parents, but in radiologic examination there was history of fracture in different site from his present illness.

Other clinical features of OI include disproportionate body, blue / gray sclera, and dentinogenesis imperfecta. Bone malformations can include abnormal rib shape in the form of pectus carinatum or pectus excavatum, long curved bones, compression of the vertebrae, scoliosis, kyphosis, and abnormal skull shape [3,5]. Head circumference can be larger than average or the head appears relatively larger large body of the sufferer. The large crown closes longer than usual, and there may be wormian bone, triangular face shape, and deafness can appear in young adulthood. Older children will appear to be well nourished or more because of their short stature. Gross motor development is delayed due to joint weakening, hypotonus or the resulting fracture [6].

The newest classification divides OI into 8 types. Type I-IV is a classification that divides OI based on clinical, radiological, and genetic aspects. Types V-VIII are types of OI that are not associated with the collagen I gene mutation and do not show a characteristic clinical picture. Type I and IV are the most common types so that they affect 4-5 of the 100,000 population in the world. The main characteristic of OI is bone fragility which increases in severity according to the order of type I <type IV, V, VI, VII <type III, VIII < type II (Table 1) [7] In this case, the patient had triangular face, a gray sclera, wide forehead, small jaw, and dentinogenesis imperfecta. Currently the patient's nutritional status is good nutrition with a short stature. The gross motor development of the sufferer is late. Patients according to OI type IV.

Table 1. Classification of osteogenesis imperfecta.

\begin{tabular}{|c|c|c|c|}
\hline Type & Gene mutation & Inheritance & Characteristics \\
\hline I & $\begin{array}{l}\text { Premature stop codon } \\
\text { at COL1A1 }\end{array}$ & $\begin{array}{l}\text { Autosomal } \\
\text { Dominant }\end{array}$ & $\begin{array}{l}\text { Mild fragility, minimal deformity, normal or slightly shorter stature, minimal scoliosis, blue sclera, rarely } \\
\text { dentinogenesis imperfecta, hearing loss } 50 \% \text {. }\end{array}$ \\
\hline II & $\begin{array}{l}\text { Glisin substitution at } \\
\text { COL1 A1 or COL1A2 }\end{array}$ & $\begin{array}{l}\text { Autosomal } \\
\text { Dominant }\end{array}$ & $\begin{array}{l}\text { Severe fragility and deformity, short stature, severe scoliosis, dark blue / gray sclera, soft skull, multiple } \\
\text { fractures of ribs and long bones, usually perinatal lethargy. }\end{array}$ \\
\hline III & $\begin{array}{l}\text { Glisin substitution at } \\
\text { COL1 A1 or COL1A2 }\end{array}$ & $\begin{array}{l}\text { Autosomal } \\
\text { Dominant }\end{array}$ & $\begin{array}{l}\text { Severe fragility and deformity, short stature, severe scoliosis, variable sclera, dentinogenesis imperfecta } \\
\text { usually present, hearing loss often. }\end{array}$ \\
\hline IV & $\begin{array}{l}\text { Glisin substitution at } \\
\text { COL1 A1 or COL1A2 }\end{array}$ & $\begin{array}{l}\text { Autosomal } \\
\text { Dominant }\end{array}$ & $\begin{array}{l}\text { Moderate fragility and deformity, variable short stature, mild-moderate scoliosis, gray / normal sclera, } \\
\text { variable dentinogenesis imperfecta, some have hearing loss. }\end{array}$ \\
\hline V & unknown & $\begin{array}{l}\text { Autosomal } \\
\text { Dominant }\end{array}$ & $\begin{array}{l}\text { Moderate fragility and deformity, short stature, variable scoliosis, normal sclera, dislocation of radial } \\
\text { head, hyperplastic callus formation on long bones, no dentinogenesis imperfecta or hearing loss. }\end{array}$ \\
\hline VI & unknown & unknown & $\begin{array}{l}\text { Moderate fragility and deformity, rather short stature, variable scoliosis, normal sclera, accumulation of } \\
\text { osteoid in bone, no dentinogenesis imperfecta. }\end{array}$ \\
\hline VII & $\begin{array}{l}\text { Partial expression from } \\
\text { CRTAP }\end{array}$ & $\begin{array}{l}\text { Autosomal } \\
\text { Recessive }\end{array}$ & $\begin{array}{l}\text { Moderate fragility and deformity, short stature, moderate scoliosis, normal sclera, rhizomelia, coxa vara, } \\
\text { no dentinogenesis imperfecta or hearing loss. }\end{array}$ \\
\hline VIII & Mutation in LEPRE 1 & $\begin{array}{l}\text { Autosomal } \\
\text { Recessive }\end{array}$ & $\begin{array}{l}\text { Moderate fragility and deformity, short stature, severe scoliosis, growth disturbances, normal sclera, } \\
\text { unknown dentinogenesis imperfecta or hearing loss }\end{array}$ \\
\hline
\end{tabular}

The role of calcium and vitamin $\mathrm{D}$ in osteogenesis imperfecta is very important. Deficiency of these two substances can aggravate osteoporosis that occurs. Deficiency of vitamin D causes the absorption of calcium is not optimal and causes hypocalcemia in the serum. This is responded to by an increase in parathyroid hormone followed by the removal of calcium in the long bones to increase the serum calcium level. The cut-off point of vitamin $\mathrm{D}$ deficiency remains controversial, especially in the pediatric population. The measurement of vitamin D levels that is often used is the level of calcidiol (25 OH D). Khadim et al. reported that both vitamin $\mathrm{D}$ deficiency and insufficiency were found in the majority of patients with OI. In that study, of the 61 OI patients, 16 of them were type IV OI with the incidence of vitamin D deficiency $(25 \mathrm{OH} \mathrm{D}<20 \mathrm{ng} / \mathrm{ml}$ ) as many as 3 people $[8,9]$. In this case, the patient's serum calcium level was $8.9 \mathrm{mg} / \mathrm{dL}$ 
of calcium and examination of vitamin D levels showed that vitamin D deficiency with 25 OHD levels was $17.6 \mathrm{ng} / \mathrm{dL}$. That result showed that the primary causative of hypocalcemia and low bone mass in the patient from the suspicion of osteogenesis imperfecta.

Edouard et al. reported that serum OHD levels were associated with BMD z-scores in children and adolescents with OI types I, III and IV. It is associated with hypocalcemia as an effect of bisphosphonate treatment, so it is important to ensure adequate calcium and vitamin $\mathrm{D}$ intake before and during therapy. Vitamin D intake ranges from 400-800 IU / day and calcium intake of 400-1000 mg/day [10, 11]. General recommendations for a minimum target of 25OHD levels range from 50 to $75 \mathrm{nmol} / \mathrm{L}$, and reported $25 \mathrm{OHD}$ levels are good for preventing fractures is between 75 and $110 \mathrm{nmol} / \mathrm{L}$. Many require vitamin D supplementation at a daily dose of 2000 IU to achieve serum 25OHD concentrations above 75 $\mathrm{nmol} / \mathrm{L}$ [12]. In this case, patients received high doses of vitamin D, namely 2000 IU every day orally and will be re-evaluated 6 weeks after starting treatment, patient also got calcitriol till patient discharged from hospital.

The target of OI therapy varies depending on the phenotype and mobility of the patient. Osteogenesis imperfecta cannot be cured. Efforts to increase bone strength and reduce the number of fractures can be carried out by means of non-surgical, surgical, and medical methods such as bisphosphonates. The most commonly used nitrogen-containing bisphosphonates are pamidronate, olpadronate, ibandronate, alendronate, risedronate, and zoledronate. Bisphosphonate is currently widely used for OI therapy in children, adolescents and adults. Almost all reports involve the use of intravenous pamidronate. Intravenous pamidronate is the standard of management in children with OI. Several service centers are already using zolendronat [6, 8-12]. In this case, due to drug availability, patients was planned to given zoledronate at a dose of 0.05 $\mathrm{mg} / \mathrm{kgBW} /$ times intravenously every three to four months.

Reactions in the acute phase related to the use of zoledronate can include fever, musculoskeletal pain and vomiting. There are several recent reports mentioning other side effects of using zoledronate are symptomatic hypocalcemia and hypophophate [13]. Although there have been many reports of side effects of bisphosphonate therapy in children with OI, there are still many gaps in the knowledge of experts especially regarding the long-term outcome of treatment.

Osteogenesis imperfecta is a chronic condition that limits the life expectancy and function of the sufferer. Patients suffering from OI show multiple fractures in the long bones, bone deformities, short stature, decreased bone mineral density which causes the patient to experience disruption of activities in his daily life. The quality of life of people with osteogenesis imperfecta is very at risk of being disrupted due to repeated fractures that require hospitalization, limited activity and require a long immobilization time [14, $15]$.

\section{Conclusions}

Osteogenesis imperfecta characterized by bone fragility due to low bone mass giving an increased fracture incidence. In this case patient complaints of fracture upper and lower limbs and teeth that grow to be brown and imperfect. Laboratory findings with slightly decrease of calcium, insufficiency vitamin $\mathrm{D}$, but the parathyroid hormone shows normal. On radiographic examination showed complete fracture on left femur. The result of BMD examination was low bone mass. Patients according to OI type IV.

The medical management in OI patients were to maintain patient function and autonomy by minimizing fractures and deformities, reducing pain, maintaining comfort, improving mobilization and increasing patient independence. Therefore management of osteogenesis imperfecta in children must involve multidisciplinary knowledge such as pediatric endocrinologists, orthopedics, medical rehabilitation, child development and nutrition.

\section{References}

[1] Trejo P, Rauch F. Osteogenesis imperfect in children and adolescents - New developments in diagnosis and treatment. Osteoporos Int. 2016; 27: 3427-37.

[2] Bethesda. Osteogenesis imerfecta overview- Osteoporosis and related bone disease. National Institutes of Health. 2015.

[3] Hoyer-Kuhn H, Netzer C, Semler O. Osteogenesis imperfecta: pathophysiology and treatment. Wien Med Wochenschr. 2015; 165: 278-84.

[4] Forlino A, Marini JC. Osteogenesis imperfecta. Lancet. 2016; 387: 1657-71.

[5] Starr SR, Timothy T, Fischer R, Fischer PR. Osteogenesis imperfect: Primary care. Pediatr in Rev. 2010; 31: 54-64.

[6] Sormova L, Mazura I. Osteogenesis imperfect type I-IV, the collagenous disorders of connective tissue in Czech population. EJBI. 2011; 7: 59-64.

[7] Rauch F, Glorieux F. Osteogenesis imperfecta. Lancet. 2004; 363: 1377-85.

[8] Lee JY, So TY, Thackray J. A review on vitamin D deficiency treatment in pediatric patients. JPPT. 2013; 18 (4): 277-91.

[9] Kadhim M, Holmes L, Bober MB, Rogers KJ, Kallur A, Davey L, et al. Vitamin D status in pediatric patients with osteogenesis imperfecta. Pediatrics \& Therapeutics. 2011; 1 (2): $2-5$

[10] Edouard T, Glorieux FH, Rauch F. Predictors and cooelates of vitamin D status in Children and adolescents with osteogenesis imperfecta. 2011; 96 (10): 3193-8.

[11] Antoniazzi F, Monti E, Mottes M, Fraschini P, Brunelli P, Forlino A, et al. Current and emerging treatments for the management of osteogenesis imperfecta. Ther Clin Risk Manag. 2010; 6: 367-81.

[12] Zerwekh JE. Blood biomarkers of vitamin D status. Am. J. Clin. Nutr. 2008; 87: 1087-91. 
[13] George S, Weber DR, Kaplan P, Hummel K, Monk HM, Levine MA. Short-term safety of zoledronic acid in young patients with bone disorders: an extensive institutional experience. J Clin Endocrinol Metab. 2015; 100 (11): 4163-171.

[14] Astrom E, Soderhall S. Beneficial effect of long term intravenous bisphosphonate treatment of osteogenesis imperfecta. Arch Dis Child. 2002; 86: 356-64.
[15] Engelbert RH, Uiterwaal CS, Gerver WJ, Net JJ, Pruijs HE, Helders PJ. Osteogenesis imperfecta in childhood: Impairment and disability. a prospective study with 4-year follow-up. Archives of Physical Medicine and Rehabilitation. 2004; 85 (5): 772-8. 